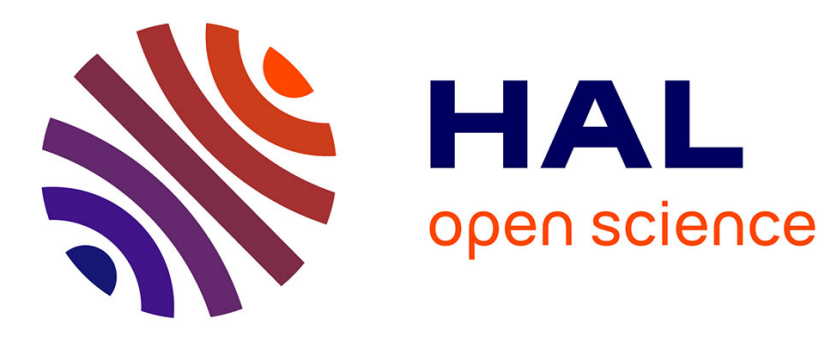

\title{
Has evidence-based medicine left quackery behind?
}

Florian Naudet, Bruno Falissard, Rémy Boussageon, David Healy

\section{To cite this version:}

Florian Naudet, Bruno Falissard, Rémy Boussageon, David Healy. Has evidence-based medicine left quackery behind?. Internal and Emergency Medicine, 2015, 10 (5), pp.631-634. 10.1007/s11739-0151227-3 . hal-01138648

\section{HAL Id: hal-01138648 \\ https://hal-univ-rennes1.archives-ouvertes.fr/hal-01138648}

Submitted on 16 Jun 2015

HAL is a multi-disciplinary open access archive for the deposit and dissemination of scientific research documents, whether they are published or not. The documents may come from teaching and research institutions in France or abroad, or from public or private research centers.
L'archive ouverte pluridisciplinaire HAL, est destinée au dépôt et à la diffusion de documents scientifiques de niveau recherche, publiés ou non, émanant des établissements d'enseignement et de recherche français ou étrangers, des laboratoires publics ou privés. 
POINT OF VIEW: Has evidence-based medicine left quackery behind?

Florian Naudet, $M D, P h D$

- Centre d'Investigation Clinique, CIC-P INSERM 1414, Centre Hospitalier Universitaire de Rennes et Université de Rennes 1, Rennes, France

- INSERM U669, Paris, France

\section{Bruno Falissard, MD, PhD}

- Université Paris-Sud and Université Paris Descartes, UMR-S0669, Paris, France - AP-HP, Hôpital Paul Brousse, Département de santé publique, Villejuif, France - INSERM U669, Paris, France

\section{Rémy Boussageon, $\mathrm{MD}, \mathrm{PhD}$}

- Faculté de médecine de Poitiers, Département de médecine générale, Poitiers, France.

\section{David Healy, MD}

- Department of Psychiatry, Bangor University, Wales UK

\section{Address for reprints / Correspondence to :}

Florian Naudet

INSERM U669, Maison de Solenn, 97 Boulevard de Port Royal, 75679 Paris cedex 14, France

tel: $(+33) 158412850$

fax: (+33) 158412843

email: floriannaudet@gmail.com 


\begin{abstract}
Evidence-Based Medicine (EBM) is generally considered as the most complete paradigm in the practice of clinical medicine. Its application should preclude all kinds of quackery. Therapeutic reformers of the second half of the 20th century have convinced the medical community that the double-blind randomized controlled trial (RCT) versus placebo is the gold standard in clinical research to establish evidence of treatment usefulness. Nevertheless, this paradigm ignores the importance of non-specific effects in the healing process and can generate misrepresentations. Additionally, because of methodological limitations, RCTs as they are used in practice can give rise to new forms of quackery by promoting drugs that are not useful for the patients who actually receive them, or are so expensive that their value is open to criticism. This is precisely the case when surrogate outcomes, with questionable clinical significance, are used. These can divert attention from clinically relevant outcomes, such as safety issues that are probably the core of treatment evaluation.

The boundaries between quackery and EBM that clinicians are faced with are not so clear-cut. There is a need for doctors to acknowledge their share in quackery and to be continually conscious of the possible pitfalls of their therapeutic practice.
\end{abstract}

\title{
Keywords :
}

Evidence based medicine; Quackery ; Clinical research ; Randomised Controlled Trials ; Epistemology 
The success of complementary or alternative medicines in managing pain, insomnia, depression, anxiety, and indeed many physical complaints, irritates many healthcare professionals. Treatments such as relaxation techniques, chiropractic, therapeutic massage, special diets, megavitamins, acupuncture, naturopathy, homeopathy, hypnosis and psychoanalysis are often considered as "pseudoscience" or "quackery" with no credible or respectable place in medicine, because in evaluation they have not been shown to "work" [12].

While psychoanalysis might be decried as a therapeutic technique, faced with a split of this sort between practice and belief, an analyst would say that there must be a defence mechanism at play here and that one explanation is that the supporters of Evidence-Based Medicine (EBM) are denying the role of quackery within their own ranks to maintain a socially acceptable image.

\section{The role of science is to debunk the healing theories of quacks}

In 1784, a "placebo" was used for the first time in a medical experiment to debunk the claims by Mesmer that he could bring about cures through "animal magnetism", a new "fluid" he said he had discovered. After a series of "placebo"-controlled experiments, it was concluded that "this fluid has no existence" and that any beneficial effects were due to "imagination" [3]. The use of a placebo became standard in experimental procedures to assess specific effects of health interventions. It enabled science to distinguish "true" (= belonging to medicine) from "false" (= belonging to quackery) hypotheses.

In the same perspective, EBM is generally considered as the most complete paradigm in the practice of clinical medicine, which "de-emphasizes intuition, unsystematic clinical experience, and pathophysiologic rationale as sufficient grounds for clinical decision-making, and stresses the examination of evidence from clinical research" [4]. More particularly, therapeutic reformers of the second half of the 20th century have convinced the medical 
community that the double-blind randomized controlled trial (RCT) versus placebo is the gold standard in clinical research to establish evidence of treatment usefulness. In this paradigm, the efficacy of an intervention is expressed as a statistically significant difference between two groups, active and placebo, ceteris paribus. The non-specific effects, controlled for by the use of a placebo, are considered as experimental noise.

\section{Evidence-Based Quackery?}

These "placebo" responses are viewed as a statistical artefact. This contrasts with the rigorous experiments on placebo that emphasize the importance of non-specific effects in the healing process, and shed new light on the ritual of the therapeutic act based on the patientphysician relationship. The therapeutic act can, in some circumstances, be as powerful as the action of a pharmacological agent [5] as shown for example in patients with asthma [6].

This type of placebo effect involves the formation of expectations and appears to have some neural basis [7]. From this point of view, interventions aiming to enhance expectations of reaching a response mediated by a biological effect could be entirely justified. Many bizarre therapeutic rituals based on hypotheses that a patient has "bought into", such as Mesmerism, can bring about unexpected benefits. In this area, patients and doctors rather than "science" define the representations that heal.

\section{The "Quack" in the Doctor}

Despite the fact that physicians increasingly use evidence-based treatments, many of the changes observed in clinical practice may not stem from specific effects of these treatments. For example, SSRIs are considered as effective medications for major depressive disorder. Concerning the outcome "response" defined as a reduction of $50 \%$ on a depression rating scale, one meta-analysis estimated a number needed to treat of 7 patients to reach one additional responder as compared with placebo [8]. This is not trivial, but given the classic response rate in placebo-controlled studies on antidepressants (40\%), among antidepressant 
responders, $75 \%$ (3/4) would have responded to placebo. However, for nearly $100 \%$ of responders, physicians and patients believe that the response is an unequivocal benefit of the active treatment.

Even if it is not intentional, in practice EBM involves an element of "quackery" when it relies on misrepresentations of this sort. While the possibility of placebo response is a reason in favour of the need for rigorous randomized controlled trials, in practice it sometimes obscures the translation of treatments efficacy into effectiveness.

\section{EBM is not efficient in detecting hidden quackery}

During the 1960s-1970s, when health authorities decided to evaluate the efficacy of new pharmaceuticals with RCTs, they in fact made a surprising choice. It should have been natural for these health authorities to find the appropriate designs and methods to answer the following questions: 1 / has this drug more positive than negative effects? $2 /$ is this drug of value when it is prescribed by real life physicians for real life patients? and $3 /$ is the price charged by the firm for the drug compatible with its usefulness? Curiously, RCTs and the statistical tests of hypothesis that conclude them provide no answers to any of these questions. $1 /$ there is no way to balance positive and negative effects in an objective manner, $2 /$ the external validity of the results is known often to be very poor and $3 /$ the economic point of view is often lacking or marginal. This generates new kinds of quackery: drugs approved by EBM but that are not useful for the real patients who receive them, or that are so expensive that their value is open to criticism.

\section{Surrogate outcomes imply surrogate Quackeries}

Additionally, in many circumstances, RCT evidence relies on the widespread use of surrogate outcomes. For example, up to 2014, no double-blind RCT has ever shown the efficacy of hypoglycaemic agents (including metformin, insulin and DPP4-inhibitors) for clinically relevant outcome measures (morbi-mortality), among which are microvascular outcomes [9]. 
HbA1c is a surrogate endpoint that is considered sufficiently reliable to substitute for relevant clinical criteria. However, several randomized trials, with a high level of evidence, disprove the idea that reducing HbA1c is necessarily beneficial for patients [10]. The most striking example is the high global and cardiovascular mortality observed in the group of intenselytreated patients in the ACCORD study [11], even though their HbA1c was $1.1 \%$ lower on average than for the controls. In the VADT study [12], with a difference of $1.5 \%$ for HbA1c between the two groups throughout follow-up (6.9\% vs $8.4 \%)$, no difference was observed on overall mortality (FR=1.08; 95\% IC 0.83-1.41), cardiovascular mortality ( $F R=1.22 ;$ IC 95\% 0.78-1.92), or non-fatal myocardial infarctions ( $F R=0.78 ; 95 \%$ IC $0.55-1.11)$. Yet this does not prevent clinicians from prescribing one or more anti-diabetic agents.

Similarly, while the wide use of pharmacotherapy for adults with alcohol use disorders has been explored by more than a hundred RCTs, there is insufficient direct evidence to determine whether or not treatment with medication leads to improvement in health outcomes (motor vehicle crashes, injuries, quality of life, function, and mortality) [13]. Trials typically focused on consumption outcomes, and the few trials that reported health outcomes were not designed or powered to assess these issues.

There are thus numerous examples of regulatory requirements that are not based on proven benefits in term of public health.

\section{EBM \& Safety}

Thus, in the area of efficacy, the boundary between quackery and EBM is not always as obvious as is assumed. Moreover, one cannot simply assume, in the short term and under certain conditions in which a treatment has demonstrated apparent efficacy relative to placebo, that it has demonstrated the required cost-benefit balance [14].

In fact, the development of evaluation techniques in medicine has been linked to safety issues [15]. A concern for safety issues is perhaps a better demarcation line between EBM and 
quackery than is a focus on efficacy. Indeed, the focus on efficacy in the 1962 amendments to the Food and Drugs Act after thalidomide aimed to improve safety [15].

RCTs became the inescapable gold standard in EBM, with some paradoxical consequences, since they do not function well for safety purposes. Randomisation can induce confounding factors wherever a treatment and an illness can produce similar or fairly similar adverse events (for example death), or if the confounding factor occurs after randomization (this is why blinding is often necessary). RCTs are underpowered to detect adverse events [16] when they are less frequent than the occurrence of the primary outcome. They cannot detect nonspecific adverse events. These so-called "nocebo" responses are here again considered as statistical artefacts and are not a matter of concern for EBM. For example it is possible that administering treatments to patients, whether these be active drugs or inert sugar tablets, may have long term harmful consequences by reducing patient perceptions of their own abilities for coping with adversity and for self-cure [14]. Additionally, in the available published evidence from RCTs, safety issues are variably and inconsistently reported [17-18]. The recent contestation of the European Medicines Agency's plans for sharing data from clinical trials by ABBVIE and INTERMUNE [19] illustrates that adverse events of treatments could be considered as "trade secrets" by some of the essential actors involved in EBM.

In other word, EBM can, in practice, sometimes hypnotise doctors into missing safety issues.

\section{Toward a rehabilitation of EBM?}

Of course, these critical views aiming to provoke reflection should be nuanced. The definition of EBM set out in this essay, essentially focusing on RCTs versus placebo (because this is the basis for EBM), is a somewhat restricted and possibly misleading definition of EBM. But we suggest that EBM has possibly evolved into something different from what it was originally intended to be. It results rather from the "contamination" of EBM by researchers not addressing the proper questions with appropriate studies, as EBM would, in theory, require. 
And indeed, the wrongful use of RCTs for surrogate outcomes, improper comparisons, and doubtful research questions are already widely addressed in the EBM literature. There is moreover a current call for a renaissance of the movement, in the form of "real evidence based medicine", refocusing on a critical examination of the pros and cons of the evidence, which can be combined with context and professional expertise in concrete circumstances. This critical approach contrasts with the vested use of EBM by industry, naïve users, and indeed "true" quacks dressed as EBM experts. Indeed, in this "real" EBM, good patient care would mean that, because we have limited data about a therapy and since we have no data about a particular patient (except maybe his prior exposures), if we are going to treat him scientifically we must accept that this is an experiment, keep a very watchful eye on what happens, and be guided by the data, not by the dictates of some wished-for or internalized model that holds sway simply because it claims to have left Quackery behind.

\section{Conclusion}

Of course, distinctions should be made between the EBM paradigm as an ideal [4] and EBM as it is implemented in day-to-day practice, which is, like all human activity, influenced by ideological or economical conflicts of interest [20].

But all in all, boundaries between quackery and the latter type of EBM (the EBM clinicians are dealing with) are far from being clear, and perhaps the distinction is not solely situated where it could be naturally expected (i.e. in the evaluation process).

Possibly the problem lies in the ability of doctors to assume their own share of quackery by not being continually conscious of the possible pitfalls of their therapeutic practice, and the limits of Science as it is implemented.

\section{Acknowledgments:}

We thank Angela Swaine Verdier for revising the English of a first version of the draft.

\section{Details of contributors}


Wrote the first draft of the paper: N.F.

Revised the paper critically for important intellectual content: B.R, F.B, HD.

Final approval of the version to be published: N.F. B.R, F.B, HD.

\section{Conflict of interests:}

There are no conflicts of interest regarding this paper. All authors have completed the Unified Competing Interest form at http://www.icmje.org/coi_disclosure.pdf (available on request from the corresponding author) and declare that (1) No authors have support from any company for the submitted work; (2) N.F. has relationships (board membership or Travel/accommodations expenses covered/reimbursed) with Servier, BMS, Lundbeck and Janssen who might have an interest in the work submitted in the previous 3 years ; B.R. has no relationships with any company that might have an interest in the submitted work in the previous 3 years; F.B has relationships (board membership or consultancy or payment for manuscript preparation or Travel/accommodations expenses covered/reimbursed) with Sanofi-Aventis, Servier, Pierre-Fabre, MSD, Lilly, Janssen-Cilag, Otsuka, Lundbeck, Genzime, Roche, BMS who might have an interest in the work submitted in the previous 3 years ; HD was expert witness for plaintiffs in 4 medico-legal cases against pharmaceutical companies for birth defects or suicide linked to antidepressants in the USA in the past 5 years.

(3) none of the authors' spouses, partners, or children have any financial relationships that may be relevant to the submitted work; and (4) none of the authors has any non-financial interests that may be relevant to the submitted work.

\section{References}

1. Bewley S, Ross N, Braillon A, Ernst E, Garrow J, Rose L, Brahams D, Baum M, Marks V, Isaacs K, May J (2011) Clothing naked quackery and legitimising pseudoscience. Bmj 343:d5960

2. Ernst E (2011) College of medicine or college of quackery? Bmj 343:d4370

3. Kaptchuk TJ, Kerr CE, Zanger A (2009) Placebo Controls, Exorcisms and the Devil. Lancet 374 (9697): 1234

4. Guyatt G, Cairns J, Churchill D, Cook D, Haynes B, Hirsh J, Irvine J, Levine M, Levine M, 
Nishikawa J, Sackett D, Brill-Edwards P, Gerstein H, Gibson J, Jaeschke R, Kerigan A, Neville A, Panju A, Detsky A, Enkin M, Frid P, Gerrity M, Laupacis A, Lawrence V, Menard J, Moyer V, Mulrow C, Links P, Oxman A, Sinclair J, Tugwell P (1992) Evidence-based medicine. A new approach to teaching the practice of medicine. Jama 268 (17):2420-2425 5. Benedetti F (2012) The placebo response: science versus ethics and the vulnerability of the patient. World Psychiatry 11 (2):70-72

6. Wechsler ME, Kelley JM, Boyd IO, Dutile S, Marigowda G, Kirsch I, Israel E, Kaptchuk TJ (2011) Active albuterol or placebo, sham acupuncture, or no intervention in asthma. N Engl J Med 365 (2):119-126. doi:10.1056/NEJMoa1103319 [doi]

7. Finniss DG, Kaptchuk TJ, Miller F, Benedetti F (2010) Biological, clinical, and ethical advances of placebo effects. Lancet 375 (9715):686-695. doi:S0140-6736(09)61706-2 [pii] 10.1016/S0140-6736(09)61706-2 [doi]

8. Arroll B, Elley CR, Fishman T, Goodyear-Smith FA, Kenealy T, Blashki G, Kerse N, Macgillivray S (2009) Antidepressants versus placebo for depression in primary care. Cochrane Database Syst Rev (3):CD007954. doi:10.1002/14651858.CD007954 [doi] 9. Boussageon R, Gueyffier F, Cornu C (2014) Effects of pharmacological treatments on micro- and macrovascular complications of type 2 diabetes: what is the level of evidence? Diabetes Metab 40 (3):169-175. doi:S1262-3636(14)00004-4 [pii]

10.1016/j.diabet.2013.12.010 [doi]

10. Boussageon R, Bejan-Angoulvant T, Saadatian-Elahi M, Lafont S, Bergeonneau C, Kassai B, Erpeldinger S, Wright JM, Gueyffier F, Cornu C (2011) Effect of intensive glucose lowering treatment on all cause mortality, cardiovascular death, and microvascular events in type 2 diabetes: meta-analysis of randomised controlled trials. Bmj 343:d4169

11. Gerstein HC, Miller ME, Byington RP, Goff DC, Jr., Bigger JT, Buse JB, Cushman WC, Genuth S, Ismail-Beigi F, Grimm RH, Jr., Probstfield JL, Simons-Morton DG, Friedewald WT (2008) Effects of intensive glucose lowering in type 2 diabetes. N Engl J Med 358 (24):2545-2559. doi:NEJMoa0802743 [pii]

10.1056/NEJMoa0802743 [doi]

12. Duckworth W, Abraira C, Moritz T, Reda D, Emanuele N, Reaven PD, Zieve FJ, Marks J, Davis SN, Hayward R, Warren SR, Goldman S, McCarren M, Vitek ME, Henderson WG, Huang GD (2009) Glucose control and vascular complications in veterans with type 2 diabetes. N Engl J Med 360 (2):129-139. doi:NEJMoa0808431 [pii] 10.1056/NEJMoa0808431 [doi]

13. Jonas DE, Amick HR, Feltner C, Bobashev G, Thomas K, Wines R, Kim MM, Shanahan E, Gass CE, Rowe CJ, Garbutt JC (2014) Pharmacotherapy for adults with alcohol use disorders in outpatient settings: a systematic review and meta-analysis. Jama 311 (18):18891900. doi:1869208 [pii] 10.1001/jama.2014.3628 [doi]

14. Middleton H, Moncrieff J (2011) 'They won't do any harm and might do some good': time to think again on the use of antidepressants? Br J Gen Pract 61 (582):47-49.

doi:10.3399/bjgp11X548983 [doi]

15. Avorn J (2012) Two centuries of assessing drug risks. N Engl J Med 367 (3):193-197. doi:10.1056/NEJMp1206652 [doi]

16. Furberg CD, Levin AA, Gross PA, Shapiro RS, Strom BL (2006) The FDA and drug safety: a proposal for sweeping changes. Arch Intern Med 166 (18):1938-1942.

doi:166/18/1938 [pii]

10.1001/archinte.166.18.1938 [doi]

17. Ioannidis JP (2009) Adverse events in randomized trials: neglected, restricted, distorted, and silenced. Arch Intern Med 169 (19):1737-1739. doi:169/19/1737 [pii]

10.1001/archinternmed.2009.313 [doi] 
18. Pitrou I, Boutron I, Ahmad N, Ravaud P (2009) Reporting of safety results in published reports of randomized controlled trials. Arch Intern Med 169 (19):1756-1761.

doi:169/19/1756 [pii]

10.1001/archinternmed.2009.306 [doi]

19. Groves T, Godlee F (2013) The European Medicines Agency's plans for sharing data from clinical trials. BMJ 346:f2961

20. Lundh A, Barbateskovic M, Hrobjartsson A, Gotzsche PC (2010) Conflicts of interest at medical journals: the influence of industry-supported randomised trials on journal impact factors and revenue - cohort study. PLoS medicine 7 (10):e1000354.

doi:10.1371/journal.pmed.1000354 